\title{
The QUTA activator and QUTR repressor proteins of Aspergillus nidulans interact to regulate transcription of the quinate utilization pathway genes
}

\author{
Heather K. Lamb, ${ }^{1}$ Giles H. Newton, ${ }^{1}$ Lisa J. Levett, ${ }^{1}$ Elaine Cairns, ${ }^{1}$ \\ Clive F. Roberts ${ }^{2}$ and Alastair R. Hawkins ${ }^{1}$
}

Author for correspondence: Alastair R. Hawkins. Tel: +44 191222 7673. Fax: +44 1912227424. e-mail: a.r.hawkins@ncl.ac.uk

\footnotetext{
1 Department of Biochemistry and Genetics, Medical School, Framlington Place, University of Newcastle, Newcastle upon Tyne NE2 4HH, UK

2 Department of Genetics, University of Leicester, Leicester LE1 7RH, UK
}

\begin{abstract}
Genetic evidence suggests that the activity of the native QUTA transcription activator protein is negated by the action of the QUTR transcription repressor protein. When Aspergillus nidulans was transformed with plasmids containing the wild-type qutA gene, transformants that constitutively expressed the quinate pathway enzymes were isolated. The constitutive phenotype of these transformants was associated with an increased copy number of the transforming qutA gene and elevated qutA mRNA levels. Conversely, when $A$. nidulans was transformed with plasmids containing the qutR gene under the control of the constitutive pgk promoter, transformants with a superrepressed phenotype (unable to utilize quinate as a carbon source) were isolated. The super-repressed phenotype of these transformants was associated with an increased copy number of the transforming qutR gene and elevated qutR mRNA levels. These copy-number-dependent phenotypes argue that the levels of the QUTA and QUTR proteins were elevated in the high-copynumber transformants. When diploid strains were formed by combining haploid strains that contained high copy numbers of either the qutA gene (constitutive phenotype) or the qutR gene (super-repressing; non-inducible phenotype), the resulting diploid phenotype was one of quinate-inducible production of the quinate pathway enzymes, in a manner similar to wild-type. The simplest interpretation of these observations is that the QUTR repressor protein mediates its repressing activity through a direct interaction with the QUTA activator protein. Other possible interpretations are discussed in the text. Experiments in which truncated versions of the QUTA protein were produced in the presence of a wild-type QUTA protein indicate that the QUTR repressor protein recognizes and binds to the C-terminal half of the QUTA activator protein.
\end{abstract}

Keywords : quinate, transcription regulation, protein-protein interaction

\section{INTRODUCTION}

Quinic acid is abundant and many prokaryotes and microbial eukaryotes are able to exploit it as a source of carbon (for a review see Hawkins et al., 1993a). In the microbial eukaryotes, as exemplified by Neurospora crassa and
Aspergillus nidulans, the quinic acid utilization pathway (qut) is completely dispensable and in wild-type strains the enzymes necessary for its catabolism are only produced when quinate is supplied exogenously. This clearly implies that this pathway is regulated, and the mechanism of this regulation has been studied in terms of the control of

Abbreviations and enzyme designations: AROM, a pentadomain protein catalysing the conversion of 3-deoxy-D-arabino-heptulosonic 7-phosphate to 5eno/pyruvyl shikimate 3-phosphate; DHQ, dehydroquinate; DHQ synthase, dehydroquinate synthase, EC 4.6.1.3; dehydroquinase, EC 4.2.1.10; DHS, dehydroshikimate; EPSP synthase, 5-eno/pyruvyl shikimate-3-phosphate synthase, EC 2.5.1.19; QUTA, positively acting protein mediating the transcriptional regulation of the quinic acid utilization gene cluster of $A$. nidulans; QUTR, negatively acting protein mediating the transcriptional regulation of the quinic acid utilization gene cluster of $A$. nidulans; shikimate dehydrogenase, EC 1.1.1.25; shikimate kinase, EC 2.7.1.71. 
pathway gene expression and the control of metabolic flux (Giles et al., 1985; Grant et al., 1988; Lamb et al., 1991, 1992; Wheeler et al., 1996). Genetic analysis of the ability to utilize quinate as a carbon source identified three classes of mutant corresponding to different complementation groups that pleiotropically affected the production of all three of the qut pathway enzymes. One class ( $q u t D$ in $A$. nidulans; $q a-Y$ in $N$. crassa) encoded a permease necessary to transport quinate into the mycelium at neutral $\mathrm{pH}$ (Whittington et al., 1987; Geever et al., 1989). A second class mainly gave rise to recessive mutations that had a non-inducible phenotype but also rarely to a dominant non-inducible phenotype. These mutations (qut $A$ in $A$. nidulans; qa- $1 \mathrm{~F}$ in $N$. crassa) were interpreted as identifying a positively acting regulatory protein. The third class was identified in $N$. crassa (designated qa-1S) in a colorimetric plate test designed to identify mutants that constitutively produced the quinate pathway enzymes in the absence of quinate (Giles $e t$ al., 1985). Such mutants were found to be recessive. In $A$. nidulans, however, the equivalent gene $(q u t \mathrm{R})$ was identified as a second-site suppressor of $q u t D$ mutations that when outcrossed conferred a recessive phenotype of constitutive production of the quinate pathway enzymes in the absence of quinate. Dominant mutations conferring the phenotype of quinate nonutilization and apparently mapping at the qa-1S and qut $A$ loci were identified in $N$. crassa and $A$. nidulans and found to revert at a high frequency to a mutant phenotype of constitutive production of the quinate pathway enzymes in the absence of quinate. This third class of mutant was interpreted as identifying a negatively acting control gene (Giles et al., 1985; Grant et al., 1988).

In both $N$. crassa and $A$. nidulans, the genes involved in the utilization of quinate and its wild-type regulation have been shown to map in a cluster. In both species, the entire gene cluster has been isolated and the genes encoding the quinate pathway enzymes shown to be regulated at the level of transcriptional control (Geever $e$ t al., 1989; Lamb et al., 1990; Levesley et al., 1996). The $A$. nidulans QUTA activator protein (encoded by qut $A$ ) controls the production of its own mRNA and that of the qut R repressor gene in an autoregulatory circuit (Levesley et al., 1996), and it contains a putative zinc binuclear cluster motif (which has been shown to bind zinc in vitro), which is proposed to facilitate binding to variants of a $16 \mathrm{nt}$ motif found in the promoters of qut pathway genes (Beri et al., 1987; Hawkins et al., 1988; Levesley et al., 1996). A similar situation exists in $N$. crassa (Geever et al., 1989).

The repressing effect of the QUTR and QA-1S proteins has been proposed to be negated by the binding of one or more of the qut pathway metabolites - quinate, 3-dehydroquinate (DHQ), shikimate or dehydroshikimate (DHS) (Hawkins et al., 1992). The binding of these intermediates is implied to cause some allosteric change in the repressor protein which negates its repressing function. These putative allosteric changes could range from subtle changes in the overall shape of the repressor protein to a complete dissociation of the proposed activator-repressor complex. This model arises from the observation that either the exogenous supply of quinate or the endogenous supply of DHQ leaking from a mutant form of the shikimate pathway AROM pentafunctional enzyme lacking 3-dehydroquinase activity leads to the production of the quinate utilization pathway enzymes (Case et al., 1972; Giles, 1978). A potential molecular mechanism for this proposed series of complex recognition events has been identified in the proposal that the quinate pathway activator and repressor proteins are homologous with shikimate pathway enzymes that recognize the quinate-pathway-activating metabolites (or closely similar molecules) as substrates (Hawkins et al., 1992, 1993a; Bugg et al., 1991; Hawkins \& Lamb, 1995). The activator protein is proposed to be homologous with the two N-terminal domains (DHQ synthase and EPSP synthase), and the QUTR protein is proposed to be homologous with the three C-terminal domains (shikimate kinase, 3-dehydroquinase and shikimate dehydrogenase) of the pentafunctional AROM enzyme active in the shikimate pathways of $A$. nidulans and $N$. crassa (Charles et al., 1986; Hawkins, 1987; Anton et al., 1987; Hawkins et al., 1992, 1993a, b). Biophysical analysis of the proposed homologous AROM 3-dehydroquinase and the QUTR 3-dehyroquinase-like domains has shown that they have similar physical characteristics that derive from a highly conserved tertiary structure (Lamb et al., 1996). Recent analysis of the nucleotide sequence of 13 qut $A$ mutations has confirmed the bi-domain structure of the QUTA protein and has located a transcription activation function (TAF) in the C-terminal EPSP-synthase-like domain (Levesley et al., 1996). These two observations lend some credence to the evolutionary hypothesis for the origins of the quinate pathway activator and repressor proteins, and in this communication we address the question of how these two proteins interact to regulate the transcription of the qut gene cluster in response to the presence of quinate.

\section{METHODS}

Plasmids, recombinant lambda and strains. The origins of the recombinant phage lambda and plasmids, other than those constructed as part of the research described here, have been described previously (Hawkins et al., 1985; Beri et al., 1987, 1990; Moore \& Hawkins, 1993; Lamb et al., 1990). The Escherichia coli strains used have been described previously, as have methods for their growth and propagation (Kinghorn \& Hawkins, 1982; Grant et al., 1988; Hawkins \& Smith, 1991; Lamb et al., 1992). The genotypes of the $A$. nidulans strains used are given in Table 1.

Materials. Chemicals and solvents other than DHQ were of AnalaR or greater purity and were purchased from local suppliers. DHQ was made from quinate and purified by chromatography as described by Grewe \& Haendler (1966). Quinate and NAD were from Sigma and dehydroshikimate (DHS) was made enzymically from DHQ using either purified type I 3-dehydroquinase from Salmonella typhi or type II 3dehydroquinase from Mycobacterium tuberculosis (Moore et al., 1992). General molecular biology reagents were from Pharmacia or Gibco BRL; Taq polymerase was from BCL. Specific 30-mer oligonucleotides were purchased from the University of Newcastle upon Tyne Central Facility for Molecular Biology, and Dynabeads were from Dynal UK. 
Table 1. Genotypes of $A$. nidulans strains

\begin{tabular}{|c|c|c|c|}
\hline Strain & Genotype & Comments & Reference \\
\hline $\mathrm{R} 153$ & w $A 3 ;$ pyro $A 4$ & & Grant et al. (1988) \\
\hline $\mathrm{R} 21$ & y $A 2 ; p a b a A 1$ & & Grant et al. (1988) \\
\hline qutE208 & yA2; qutE208; pabaA1 & & Grant et al. (1988) \\
\hline G191 & fw $A 1 ;$ pyrG189; paba $A 1 ;$ uaY9 & & Lamb et al. (1990) \\
\hline qut $A 303$ & wA3; pyro $A 4 ;$ qut $A 303$ & & Grant et al. (1988) \\
\hline 2035 & yA2; pyrG189; qut $\mathrm{R}^{c}$ & & Lamb et al. (1992) \\
\hline 2043 & fw $A 1 ;$ pyrG189; paba $A 1 ;$ uaY9 & $\begin{array}{l}\text { Strain G191transformed } \\
\text { with plasmid pCAP2, } \\
\text { containing the } N \text {. crassa } \\
\text { pyr-4 gene }\end{array}$ & This work \\
\hline
\end{tabular}

Methods. Restriction endonucleases were used according to the manufacturer's recommendations. PCR amplification of target DNA sequences was as described previously (Van den Hombergh et al., 1992; Moore \& Hawkins, 1993). All other routine molecular biology protocols followed individual manufacturer's recommendations or were as described by Maniatis et al. (1982). DNA was labelled using a Boehringer Mannheim randomprimed DNA-labelling kit, and the labelled probe purified using the NucTrap purification column system from Stratagene. Quinate dehydrogenase, 3-dehydroquinase and dehydroshikimate dehydratase assays were performed as described previously (Grant et al., 1988). Transformation of $A$. nidulans and the preparation of cell-free extracts for enzyme assay were as previously described (Lamb et al., 1991; Grant et al., 1988). An in vitro colour test, the 'PCA spot test' was used to detect the presence of quinate pathway enzymes in young mycelium and was carried out as described by Grant et al. (1988). This test traps the product of the quinate utilization pathway (protocatechuic acid; PCA) as a highly coloured compound after reaction with iron. This purple-coloured compound is easily visible by eye and can be measured accurately spectrophotometrically (Van den Hombergh et al., 1992) when used in pathway flux experiments. However when used as a test for constitutivity using a single measurement the test is only semi-quantitative, but it easily and accurately identifies constitutive transformants. Purification of total RNA followed the method of Cathala $e t$ al. (1983) and poly $\left(\mathrm{A}^{+}\right) \mathrm{mRNA}$ was prepared from total RNA using Dynabeads Oligo(dT) and following the manufacturer's protocol. Images from Southern and Northern-blot experiments that involved the qut $A, q u t \mathrm{R}$ and act $A$ genes of $A$. nidulans were recorded by quantitative phosphoimaging, using a Molecular Dynamics phosphoimager model $400 \mathrm{~b}$ and analysed using Imagequant software version 3.3. Exposures of the probed filters varied between $1 \mathrm{~h}$ (for high-copy-number transformants) and $48 \mathrm{~h}$ (for low-expressed wild-type regulatory gene mRNA levels). Copy number of the qut $A$ gene in Southern blots of transformant DNA was quantified by comparison of duplicate dot-blots probed with the qut $A$ gene or the act $A$ gene of $A$. nidulans (Fidel et al., 1988). Copy number of the qut $\mathrm{R}$ gene in Southern blots of transformant DNA was quantified by reference to the intensity of the signal produced by the resident $q u t \mathrm{R}$ gene, as only transformants with integration events away from the resident qut gene cluster were utilized in subsequent analysis.

Construction of $\boldsymbol{A}$. nidulans expression vectors and recombinant derivatives expressing the qa-2, qut $R$ and qutA genes. Plasmid pNUFC77 contains the $A$. nidulans qut $E$ promoter and terminator sequences separated by a short polylinker region containing NcoI, Pst I and HindIII recognition sites, and additionally has translational stop codons in all three reading frames immediately downstream of the terminator sequence (Moore \& Hawkins, 1993). The qutE promoter region of pNUFC77 was removed by digestion with SacI and NcoI and replaced with the promoter region from the $A$. nidulans phosphoglycerate kinase ( $p g k)$ gene, a promoter that has constitutive activity (Clements \& Roberts, 1986). The promoter region from the $p g k$ gene extended from the $A$ base preceding the AUG translational codon upstream for a further $372 \mathrm{nt}$. 'This promoter region was amplified by PCR using oligonucleotides containing recognition sites for $S_{a c} \mathrm{I}$ (the upstream site) or $\mathrm{NcoI}$ (the downstream site), and following digestion with SacI and NcoI was subcloned into appropriately digested pNUFC77 to yield pNUFC100. The pUC18 backbone in plasmids pNUFC77 and 100 contains a unique $N d e I$ site located outside of the general-purpose polylinker (which is deleted in these constructs); this site was replaced with a unique $X b a I$ site in plasmids pNUFC77 and 100 by site-directed mutagenesis. This was achieved by PCR using 'back-to-back' oligonucleotides, one of which contained the required $X b a \mathrm{I}$ site, as described by Hemsley et al. (1989) and modified by Moore \& Hawkins (1993). This mutagenesis produced plasmids pNUFC101 (modified $\mathrm{pNUFC100)}$ ) and pNUFC102 (modified pNUFC77). Plasmid pNUFC200 was constructed by subcloning PCR-amplified DNA containing the qa-2 coding sequence into plasmid pNUFC101. The amplified sequence was flanked by $N$ coI and HindIII sites at the $5^{\prime}$ and $3^{\prime}$ ends of the gene, respectively, and after suitable digestion was subcloned into the vector pNUFC101. The $N$. crassa pyr-4 gene was amplified by PCR from plasmid pFB4 and, in addition to the coding sequence, contained the first 219 nucleotides of the upstream $5^{\prime}$ noncoding region and the first 165 nucleotides of the $3^{\prime}$ non-coding region. The oligonucleotides for PCR of the pyr-4 gene contained recognition sites for $X b a \mathrm{I}$ and, following appropriate digestion, the PCR-amplified DNA was subcloned in XbaIdigested pUC18 DNA. In all cases, modified plasmids were rescued from ligation mixtures by transforming $E$. coli strain SK3430 and selecting transformants on rich medium containing $50 \mu \mathrm{g}$ ampicillin $\mathrm{ml}^{-1}$. Individual plasmid constructs were verified by digesting plasmid DNA with appropriate restriction endonucleases. The oligonucleotides used in the various PCR amplifications were: the $p g k$ promoter upstream oligonucleotide, 5' CGATGTATAACTGAGCTCAGGAACGGAGCG $3^{\prime}$; the $p k g$ promoter downstream oligonucleotide, $5^{\prime}$ TGCTGGTGAGAGCCATGGTTGCTATAGCTG $3{ }^{\prime}$; the mutagenic oligonucleotide to produce an $X b a \mathrm{I}$ site into pNUFC77 and 100, 5' CTGAGAGTGCACTCTAGACGGTGTGAAATA $3^{\prime}$; the non-mutagenic oligonucleotide to introduce an XbaI site into pNUFC77 and 100, 5' TACA- 
ATCTGCTCTGATGCCGCATAGTTAAG $3^{\prime}$; the pyr-4 gene upstream oligonucleotide, 5' AATTCACGCTGATCTAGAAAACATTGTGCA $3^{\prime}$; the pyr-4 downstream oligonucleotide, $5^{\prime}$ GCCTTACAAATCTAGATGGTAGTTTCT'T $3^{\prime}$; the $5^{\prime}$ qa-2 oligonucleotide, 5' GAGGTACCAAACACCATGGCGTCCCCCCGT 3'; the $3^{\prime}$ qa-2 oligonucleotide, 5' CATCCCAATGCAAAGCTTCAAAACTTCATGT $3^{\prime}$. The template for the pgk promoter PCR was plasmid pGK1 (Clements \& Roberts, 1985), for the pyr-4 gene it was plasmid pFB4 (Buxton \& Radford, 1983) and for the qa-2 gene it was pVK88 (Giles et al., 1985).

The purpose behind producing pNUFC101 and 102 was to provide vectors containing a unique $\mathrm{XbaI}$ site, to facilitate the subcloning of the selectable marker pyr-4 (Buxton \& Radford, 1983; Glazebrook et al., 1987) thereby allowing indirect selection for any other sequence cloned into the plasmids. The $q u t A, q u t \mathrm{R}$ and $p y r-4$ genes do not contain $X b a \mathrm{I}$ sites; therefore by prior subcloning of qut $A$ or qut $R$ into these vectors it should be possible to introduce them into $A$. nidulans by indirect selection using the pyr-4 selectable marker cloned into the $X b a \mathrm{I}$ site.

Initial experiments showed that the pyr-4 gene, when amplified by PCR using oligonucleotides incorporating $\mathrm{XbaI}$ sites, could not be subcloned into the XbaI site of pNUFC101 and 102 following suitable digestion. Subsequently, however, the pyr-4 gene was successfully subcloned into the $\mathrm{XbaI}$ site in pUC18 to yield pNUFC247 and shown to complement the pyrG189 mutation. When pyr- 4 was released from pNUFC247 by $X b a \mathrm{I}$ digestion, and purified by gel electrophoresis, it was found that it could be easily subcloned into the XbaI site in pNUFC101 or 102 or recombinant plasmids derived from them. The reason for the difficulty in subcloning fragments of DNA prepared by the direct digestion of the products of a PCR remains unclear. We were able to routinely subclone the products of a PCR provided that the ends were generated by digestion with different restriction endonucleases. If, however, the ends were generated by the same restriction endonuclease we experienced great difficulty and, in some cases, were unable to subclone the fragment and had to employ the alternative strategies described below to construct the plasmids needed.

Experiments with the qut $A$ gene made use of the fact that it does not contain a $B g / I I$ site and that the $A$. nidulans vector $\mathrm{pCAP} 2$ (Turner \& Ballance, 1987), has a unique BamHI site in addition to the selectable marker $p y r-4$. Sequences of the whole qut $A$ gene or parts thereof were subcloned into pNUFC101 or 102 and subsequently amplified by PCR, using oligonucleotides specific to the promoter and terminator and containing $B g / \mathrm{II}$ sites. These PCR products therefore contain the qut $A$ sequences fused to the qutE or $p g k$ promoter and the qutE terminator. Following appropriate digestion, the qut $A$ sequences could then be successfully subcloned into the BamHI site of pCAP2, thereby allowing transformation into $A$. nidulans using the $p y r-$ 4 selectable marker. This strategy was adopted because at the time of construction it was not possible to utilize the strategy of subcloning in the selectable pyr-4 marker (see above). qut $A$ and qut $\mathrm{R}$ DNA sequences of the coordinates shown in Table 4 were amplified by PCR using $5^{\prime}$ and $3^{\prime}$ oligonucleotides that contained $N c o I / B s p \mathrm{HI}$ or HindIII sites, respectively, at the $5^{\prime}$ and $3^{\prime}$ ends of the target DNA (see below). After suitable digestion, the DNA sequences were subcloned into the vectors pNUFC77 or 101 , placing them under the control of the qut $E$ or $p g k$ promoters and the qutE terminator. Oligonucleotides specific to the $5^{\prime}$ end of the pgk promoter and the $3^{\prime}$ end of the qut $E$ terminator and containing restriction sites for $B g / I I$ were used to PCR-amplify the qut $A$ DNA sequences in plasmids pNUFC77 or 101 as a cassette with the promoter and terminator attached. Following appropriate digestion with restriction endonucleases the PCRamplified DNA sequences were subcloned in the transformation vector pCAP2 at a unique $\mathrm{BamHI}$ site. Plasmid pCAP2 carries the $N$. crassa pyr-4 gene, allowing selection for transformants on the basis of uracil independence in strains wild-type for the qut gene cluster, but carrying the pyr-G mutation.

qut $\mathrm{R}$ DNA sequences of the coordinates shown in Table 4 were amplified by the PCR using oligonucleotides containing $5^{\prime}$ and $3^{\prime}$ NcoI sites, and after suitable digestion, subcloned into the vector pNUFC101. Subsequently the recombinant pNUFC101 plasmids were digested with $X b a I$ and the pyr-4 gene from pNUFC247 subcloned on an $X b a I$ fragment.

The $5^{\prime}$ oligonucleotide for the complete qut $A$ gene was $5^{\prime}$ TCATTGTATCGATCATGAGTAGCGATA $3^{\prime}$; the $3^{\prime}$ oligonucleotides for the complete qut $A$ gene was $5^{\prime}$ GTGCAGAAGAGATCATGAT'TACCTATCTG'T $3^{\prime}$; the $5^{\prime}$ oligonucleotide to the promoter in pNUFC101 was $5^{\prime}$ CGGCC AG'TGCCAAGA'TCT'T'TCATGCAGAAT 3'; the $3^{\prime}$ oligonucleotide to the terminator in pNUFC101 was $5^{\prime}$ ACGAAT'TAA'T'TCAGATC'TAGGAACGGAGCC $3^{\prime}$; the $5^{\prime}$ oligonucleotide for the complete qut $\mathrm{R}$ gene was $5^{\prime}$ CTGATCCACCTGCCATGG'TTCATGCGTTCT $3^{\prime}$; the $3^{\prime}$ oligonucleotide for the complete qut $R$ gene was $5^{\prime}$ ACAAGCGTGGCCCCATGGTCACATCGGCTG $3^{\prime}$; the $5^{\prime}$ oligonucleotide for the qut $A$ sequence in pATR3 was $5^{\prime}$ CTGGCAACCATCATGAAAGAGTCGGAGGGG $3^{\prime}$; the $5^{\prime}$ oligonucleotide for the qut $A$ sequence in pATR4 was $5^{\prime}$ CTGGCAACCATCATGAAAGAGTCGGAGGGG 3'; the 3' oligonucleotide for the qut $A$ sequence in pATR4 was $5^{\prime}$ GTGCTGAGATCATGAAGTCACCCGCGTTGG 3'.

\section{RESULTS AND DISCUSSION}

\section{Construction of $\boldsymbol{A}$. nidulans expression vectors}

In order to be able to decouple the expression of the qut $A$ and qut $\mathrm{R}$ genes and fragments thereof from the autoregulatory circuit mediated by the QUTA protein, $A$. nidulans expression vectors utilizing the constitutive phosphoglycerate kinase $(p g k)$ promoter were constructed. These vectors were constructed as part of a larger exercise designed to produce general expression vectors for $A$. nidulans with either inducible or constitutive promoters. Expression vectors utilizing the quinate-inducible qutE promoter or the constitutive $p g k$ promoter (Clements \& Roberts, 1985, 1986) were constructed using pUC18 as a backbone. The construction of pNUFC77 (which contains a quinate-inducible promoter) has been described previously (Moore \& Hawkins, 1993), and the construction of plasmids pNUFC100,101 and 102 is described in Methods. The qutE promoter in pNUFC77 has previously been shown to drive effective transcription of heterologous genes in A. nidulans (Lamb et al., 1991; Moore et al., 1992; Moore \& Hawkins, 1993).

The control of transcription by the $A$. nidulans pgk promoter has been analysed in detail previously, and was shown to be positively influenced by the sequence of the pgk chromosomal gene encompassing codons 14-183 and including two introns (Streatfield et al., 1992). In order to assess the ability of the isolated pgk promoter - in the absence of the sequences from the $p g k$ gene - to drive heterologous gene expression in pNUFC101, the $q a-2$ gene of $N$. crassa encoding a type II 3-dehydroquinase was 


\section{Table 2. Description and testing of $A$. nidulans expression vectors}

Plasmid characteristics are shown in (a). In (b), cell-free extracts of uninduced (U) or induced (I) mycelium prepared from the control wild-type (R153), two transformants of strain qutE208 transformed with pEH1 (TE1 and 2), and five experimental strains of qutE208 transformed with pNUFC200 (TQ1-5) grown in minimal medium with glucose as carbon source were assayed for the presence of quinate pathway enzymes. Activities are expressed relative to the value in the R153 control, which has a wild-type qut gene cluster. Specific activities are shown in parentheses. ND, Not detectable.

\section{(a) Plasmid characteristics}

\begin{tabular}{|lcclcl|}
\hline Plasmid & Vector & Backbone & Promoter & Terminator & Other features \\
\hline pNUFC77 & NA & pUC18 & $q u t E$ & $q u t E$ & \\
pNUFC100 & NA & pUC18 & $p g k$ & $q u t E$ & \\
pNUFC101 & pNUFC100 & pUC18 & $p g k$ & $q u t E$ & Unique $N d e I \rightarrow X b a \mathrm{I}$ \\
pNUFC102 & pNUFC77 & pUC18 & $q u t E$ & $q u t E$ & Unique $N d e \mathrm{I} \rightarrow X b a \mathrm{I}$ \\
pNUFC200 & pNUFC101 & pUC18 & $p g k$ & $q u t E$ & $\begin{array}{c}\text { Drives transcription of } \\
\text { the } N . \text { crassa qa-2 } \\
\text { gene }\end{array}$ \\
pNUFC247 & NA & pUC18 & NA & NA & $\begin{array}{c}\text { Contains the N. crassa } \\
\text { pyr-4 gene }\end{array}$ \\
\hline
\end{tabular}

NA, Not applicable.

(b) Ability of the isolated pgk promoter to drive constitutive transcription

\begin{tabular}{|c|c|c|c|c|c|c|}
\hline \multirow[t]{2}{*}{ Strain } & \multicolumn{2}{|c|}{$\begin{array}{c}\text { Quinate } \\
\text { dehydrogenase }\end{array}$} & \multicolumn{2}{|c|}{ 3-Dehydroquinase } & \multicolumn{2}{|c|}{$\begin{array}{c}\text { Dehydroshikimate } \\
\text { dehydratase }\end{array}$} \\
\hline & $\mathbf{U}$ & I & $\mathbf{U}$ & I & $\mathbf{U}$ & I \\
\hline R153 & ND & $1.00(0.090)$ & ND & $1.00(0.285)$ & ND & $1.00(0 \cdot 179)$ \\
\hline TE1 & ND & $0.80(0.073)$ & ND & $0.73(0.219)$ & ND & $1.00(0 \cdot 179)$ \\
\hline TE2 & ND & $1.25(0.113)$ & ND & $0.20(0.058)$ & ND & $0.97(0.174)$ \\
\hline TQ1 & ND & $1 \cdot 21(0 \cdot 110)$ & $2.60(0.750)$ & $2.60(0.750)$ & ND & $1.04(0.187)$ \\
\hline TQ2 & ND & $0.85(0.077)$ & $0.88(0.250)$ & $0.88(0.025)$ & ND & $0.97(0.174)$ \\
\hline TQ3 & ND & $0.90(0.080)$ & $3.80(1.090)$ & $4 \cdot 50(1 \cdot 300)$ & $\mathrm{ND}$ & $0.96(0 \cdot 172)$ \\
\hline TQ4 & ND & $0.87(0.079)$ & $5.80(1.670)$ & $5 \cdot 70(1 \cdot 640)$ & ND & $1.01(0 \cdot 182)$ \\
\hline TQ5 & ND & $0.69(0.063)$ & $0 \cdot 25(0 \cdot 071)$ & $0.33(0.094)$ & ND & $0.92(0.167)$ \\
\hline
\end{tabular}

amplified by PCR and subcloned into pNUFC101 to yield pNUFC200 (see Table 2a). A. nidulans strain qutE208, which is a mutant strain unable to grow on quinate as sole carbon source because it lacks the type II 3-dehydroquinase, was transformed with pNUFC200 and transformants were selected by growth on minimal medium with quinate as sole carbon source. As a control, $A$. nidulans strain qutE208 was transformed with pEH1, which contains the qutE gene encoding a type II 3dehydroquinase (Beri et al., 1990), and with pTR101, which contains the $q a-2$ gene under the control of the $E$. coli trc promoter (Hawkins et al., 1993c).

Individual transformants were streaked for single colonies on selective medium, grown in bulk and 3-dehydroquinase assays performed on cell-free extracts as described previously (Grant et al., 1988; Lamb et al., 1991). The results of these assays on control and experimental transformants (containing the qa-2 gene under the control of the $p g k$ promoter) are shown in Table 2(b); the results show that the $p g k$ promoter in pNUFC200 can drive efficient constitutive transcription of heterologous cloned genes with, in this instance, enzyme levels up to $5 \cdot 8$-fold over the wild-type value.

The use of the qa-2 gene here was merely to confirm that the $p g k$ promoter, lacking the sequences of the $p g k$ gene that positively affect transcription, drives constitutive transcription when taken out of its usual context and placed in pNUFC101. As direct selection for the function of the qa-2 gene was used in this experiment, it is possible to argue that these transformants contain complex rearrangements that fuse the qa-2 genes to unidentified constitutive promoters. This explanation can be precluded for three reasons: firstly, control experiments utilizing pTR101, which contains the qa-2 gene cloned into the $E$. 
Table 3. Constitutive expression of qut pathway enzymes in strains transformed with the complete or truncated forms of the qutA gene

Cell-free extracts from control and transformed strains were screened for the production of quinate pathway enzymes under conditions of quinate induction (I) or uninduced (U). Each enzyme assay was carried out once, separately and in conjunction with appropriate control PCA spot tests (spot test results: I, inducible; NI, non-inducible; $c$, constitutive). In all cases enzyme activities are expressed relative to the value in the control, which has a wild-type qut gene cluster. Specific activities of the enzymes are shown in parentheses. ND, Not detectable. Strains: (a) wild-type (R153) control, qut A303 and three transformants (TATR1, TATR2, TATR95) transformed with plasmid pAL7 $\triangle \mathrm{GE}$; (b) control transformant (2043) transformed with unmodified PCAP2 and four transformants (TATR41, 43, 44, 45) that were transformed with plasmid pNUFC201 containing the qut $A$ gene in the vector pNUFC101 and were positive in the PCA spot test; (c) control transformant (2043) transformed with unmodified PCAP2, one inducible transformant (TATRK189) and three transformants that were constitutive in the PCA spot test transformed with plasmid pATR3.

\begin{tabular}{|c|c|c|c|c|c|c|c|}
\hline \multirow[t]{3}{*}{ Strain } & \multirow{3}{*}{$\begin{array}{c}\text { PCA } \\
\text { spot } \\
\text { test }\end{array}$} & \multicolumn{2}{|c|}{ Quinate dehydrogenase } & \multicolumn{2}{|c|}{ 3-Dehydroquinase } & \multirow{2}{*}{\multicolumn{2}{|c|}{$\begin{array}{c}\text { Dehydroshikimate } \\
\text { dehydratase }\end{array}$}} \\
\hline & & \multirow[t]{2}{*}{$\mathbf{U}$} & \multirow[t]{2}{*}{$\mathbf{I}$} & \multirow[t]{2}{*}{$\mathbf{U}$} & \multirow[t]{2}{*}{$\mathbf{I}$} & & \\
\hline & & & & & & $\mathbf{U}$ & $\mathbf{I}$ \\
\hline \multicolumn{8}{|c|}{ (a) Expression of the complete qutA gene driven by the native qutA promoter } \\
\hline R153 & I & ND & $1 \cdot 0(0 \cdot 142)$ & $\mathrm{ND}$ & $1 \cdot 0(0 \cdot 125)$ & ND & $1 \cdot 0(0 \cdot 136)$ \\
\hline qut $A 303$ & NI & ND & ND & ND & ND & ND & ND \\
\hline TATRA1 & I & ND & $1 \cdot 0(0 \cdot 141)$ & ND & $1 \cdot 4(0 \cdot 176)$ & ND & $1 \cdot 3(0 \cdot 170)$ \\
\hline TATRA2 & c & $1 \cdot 3(0 \cdot 190)$ & $1 \cdot 1(0 \cdot 158)$ & $1 \cdot 7(0 \cdot 210)$ & $1 \cdot 0(0 \cdot 130)$ & $1 \cdot 0(0 \cdot 140)$ & $0 \cdot 8(0 \cdot 110)$ \\
\hline TATRA95 & $\mathrm{c}$ & $1 \cdot 1(0 \cdot 155)$ & $1.9(0.270)$ & $1 \cdot 2(0 \cdot 150)$ & $3 \cdot 0(0 \cdot 380)$ & $1 \cdot 0(0 \cdot 136)$ & $2 \cdot 4(0 \cdot 320)$ \\
\hline \multicolumn{8}{|c|}{ (b) Expression of the complete qut $A$ gene driven by the $p g k$ promoter } \\
\hline 2043 & I & ND & $1 \cdot 0(0 \cdot 041)$ & ND & $1.00(0 \cdot 220)$ & ND & $1 \cdot 00(0 \cdot 051)$ \\
\hline TATRK41 & c & $0.34(0.014)$ & $2.5(0 \cdot 103)$ & $0.32(0.070)$ & $0.47(0.104)$ & $0.12(0 \cdot 006)$ & $1 \cdot 18(0.060)$ \\
\hline TATRK43 & C & $1.20(0.052)$ & $4 \cdot 3(0 \cdot 178)$ & $0.86(0.019)$ & $0.41(0.090)$ & $0.59(0.030)$ & $1.98(0 \cdot 101)$ \\
\hline TATRK44 & C & $1 \cdot 00(0 \cdot 044)$ & $2 \cdot 5(0 \cdot 105)$ & $0.68(0 \cdot 150)$ & $0.63(0.139)$ & $0 \cdot 94(0 \cdot 048)$ & $2 \cdot 37(0 \cdot 121)$ \\
\hline TATRK45 & $\mathrm{C}$ & $0.90(0.040)$ & $1.4(0.059)$ & $0.42(0.093)$ & $0.82(0.180)$ & $0.88(0.045)$ & $1 \cdot 18(0 \cdot 060)$ \\
\hline \multirow{2}{*}{\multicolumn{8}{|c|}{$\begin{array}{c}\text { (c) Expression of the qutA gene lacking the sequence encoding the amino-terminal } 32 \text { amino acids, and driven by the } \\
\text { pgk promoter }\end{array}$}} \\
\hline & & & & & & & \\
\hline 2043 & I & $0.03(0.005)$ & $1 \cdot 00(0 \cdot 183)$ & $0 \cdot 11(0 \cdot 005)$ & $1 \cdot 00(0 \cdot 045)$ & ND & $1.00(0.194)$ \\
\hline TATRK189 & I & $0.09(0.017)$ & $0.54(0.098)$ & $0.06(0.003)$ & $0.77(0.035)$ & $0.07(0 \cdot 112)$ & $0.97(0.122)$ \\
\hline TATRK195 & c & $0.22(0.040)$ & $0.46(0.085)$ & $0.40(0.018)$ & $1.24(0.056)$ & $0 \cdot 20(0.038)$ & $0.52(0.038)$ \\
\hline TATRK202 & c & $0.23(0.042)$ & $0.40(0.074)$ & $0.60(0.027)$ & $1.04(0.047)$ & $0.17(0.033)$ & $0.56(0.033)$ \\
\hline TATRK251 & c & $0.20(0.037)$ & $0.70(0.129)$ & $0.55(0.025)$ & $0.80(0.036)$ & $0.25(0.050)$ & $0.51(0.050)$ \\
\hline
\end{tabular}

coli expression plasmid pTrc99a, never gave rise to transformants; secondly, the frequency of transformation $\left(\sim 50 \mu \mathrm{g}^{-1}\right)$ is far too high to be accounted for by complex gene rearrangements; and thirdly, Southern-blot analysis of six randomly isolated strains transformed with pNUFC200 (and subsequently digested with restriction enzymes designed to release the qa-2 PCR product) showed that all the transformants had an indistinguishable integration pattern, making it extremely unlikely that complex rearrangements were taking place fusing the qa2 gene to unidentified constitutive promoters.

\section{Increasing the copy number of the qutA gene in $A$. nidulans leads to a constitutive phenotype for the quinate utilization pathway}

Expression from the wild-type qutA promoter. $A$. nidulans strain qut $A 303$ has a mutation in the qut $A$ gene which prevents production of the quinate pathway enzymes even in the presence of quinate; this strain is therefore unable to utilize quinate as a carbon source (Grant et al.,
1988). The qut $A 303$ mutation is located within the DHQsynthase-like domain of the QUTA protein (Levesley et al., 1996).

A. nidulans strain qut $A 303$ was transformed with plasmid pAL7 $\Delta G E$, which contains the wild-type qut $A$ gene under its natural promoter (Beri et al., 1990), and transformants were selected by their ability to grow in minimal medium with quinate as carbon source. A total of 104 transformants were screened by the in vitro colour test (the PCA spot test; see Methods) for the presence of constitutively produced quinate pathway enzymes. Two transformants, designated TATRA2 and TATRA95, were identified by this screening procedure and the levels of quinate pathway enzymes in these strains and a control transformant (TATR1) with a wild-type inducible phenotype were determined in cell-free extracts of mycelium grown under inducing (quinate present) or non-inducing (quinate absent) conditions.

The results of these enzyme assays, shown in Table 3(a), demonstrate that transformants TATRA2 and TATRA95 
(a)

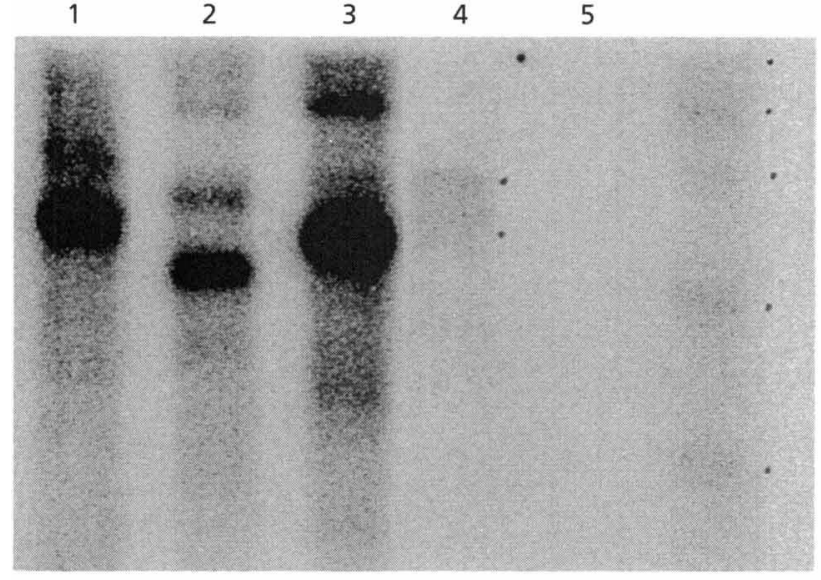

(b)

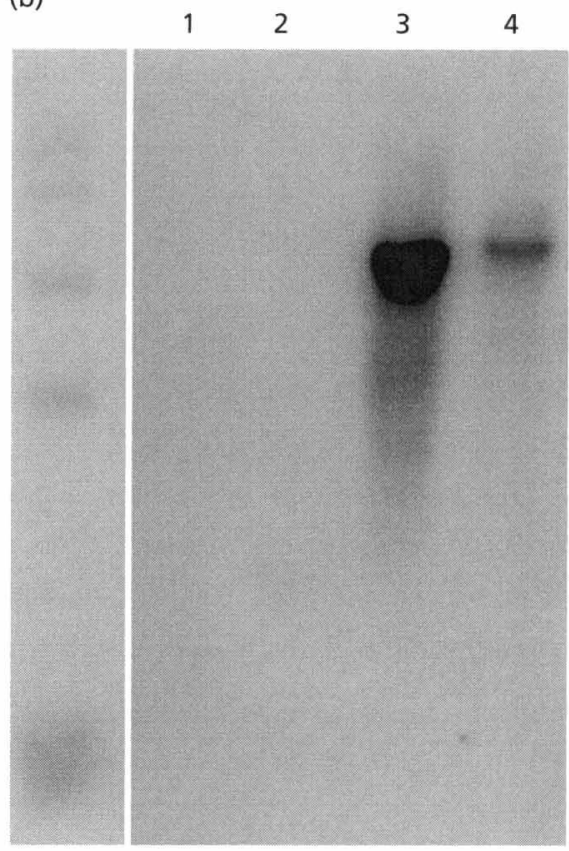

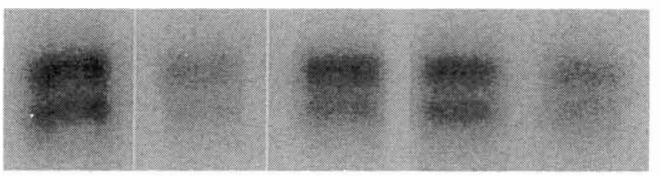

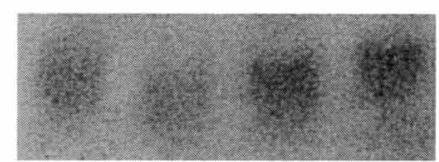

Fig. 1. (a). Northern-blot analysis of wild-type and qutA multicopy transformants. Approximately $5 \mu \mathrm{g}$ poly $\left(\mathrm{A}^{+}\right) \mathrm{mRNA}$ isolated from $A$. nidulans strains transformed with plasmids specifying the entire QUTA protein or a deleted form lacking the N-terminal 132 amino acids (and hence lacking the zinc binuclear cluster motif), and driven by the native or $p g k$ promoters, was subjected to Northern-blot analysis. Lane 1, TATRA95 multicopy qutA transformant (copy number 16; relative message level 5.2) driven by the qutA promoter, uninduced. Lane 2, TATRK251 multicopy transformant (copy number 10; relative message level 10) specifying a truncated qutA sequence lacking the $\mathrm{N}$-terminal 132 amino acids which include the zinc binuclear cluster motif, and driven by the pgk promoter, uninduced. Lane 3, TATRAK41, multicopy qutA transformant (copy number 11; relative message level 15) driven by the pgk promoter, uninduced. Lane 4, G191, wild-type positive control (copy number 1; relative message level 1), quinate-induced. Lane, 5, G191, wild-type negative control (copy number 1 ; relative message level undetectable), uninduced. The positions of the markers and qutA derived mRNA are marked with dots. (b). Northern-blot analysis of host strain and a qutR multicopy transformant, R1/27. Approximately $5 \mu \mathrm{g}$ of poly $\left(\mathrm{A}^{+}\right)$mRNA isolated from $A$. nidulans strain 2035 transformed with a plasmid specifying the entire qutR protein, and driven by the $p g k$ promoter, was subjected to Northern-blot analysis. Conidiospores were grown overnight in $0.5 \%$ glucose. Resulting mycelial samples were divided in two and grown for $4 \mathrm{~h}$ in $0.1 \%(\mathrm{v} / \mathrm{v}) \mathrm{glycerol}$ for uninduced samples and $0.1 \%(\mathrm{v} / \mathrm{v})$ glycerol plus $0.3 \%(\mathrm{w} / \mathrm{v})$ quinic acid to obtain induced samples. Lane 1, strain 2035 , induced (copy number 1; relative message level undetectable); lane 2, strain 2035, uninduced (copy number 1 ; relative message level undetectable); lane 3, strain R1/27, induced (copy number 4; relative message level 4.5); lane 4, strain $R 1 / 27$, uninduced (copy number 4 ; relative message level 0.7 ). In (a) and (b) the qutA or qutR message level, where detectable, is expressed relative to the value of the actin control. Even transfer of the various mRNA species was checked by probing for the actin-specific mRNA (the lower row of mRNA species in each case) using a radiolabelled $0.83 \mathrm{~kb}$ Ncol-Kpnl fragment from the actA gene of $A$. nidulans (Fidel et al., 1988). In both (a) and (b) the unlabelled track contains RNA size markers (1.4, 2.4, 4.4, 7.5 and $9.5 \mathrm{~kb}$, purchased from GIBCO BRL).

constitutively produce all three quinate pathway enzymes. Southern and dot-blot analysis of strains TATRA2 and TATRA95 showed that they were multi-copy transformants (10 and 16 copies respectively; data not shown) and that TATRA1 had only a single extra copy of the qut $A$ gene. In each case, however, the qut $\mathrm{R}$ (repressorencoding) gene was unaffected by the integration events, precluding the disruption of the gene as a cause of the constitutive phenotype. Northern-blot analysis of transformant TATRA95 demonstrated that a qut $A$-specific mRNA of the appropriate size was being synthesized constitutively to an elevated concentration compared with the wild-type control (see Fig. 1a).

Biological precedent suggests that the two most likely explanations of these data are that the QUTR repressor protein is being 'titrated out' either by interacting stoichiometrically with the presumed excess QUTA protein being produced by these transformants or by interaction with the multiple copies of the qut $A$ promoter. Alternative interpretations of the data are evaluated in the Conclusions. 
Table 4. Plasmids containing qutA or qutR sequences

\begin{tabular}{|c|c|c|c|c|c|c|c|}
\hline Plasmid & Vector & $\begin{array}{l}\text { Selectable } \\
\text { marker for } \\
\text { A. nidulans }\end{array}$ & Promoter & $\begin{array}{c}q u t A \\
\text { coordinates }\end{array}$ & $\begin{array}{c}q u t R \\
\text { coordinates }\end{array}$ & Encoded domain & $\begin{array}{c}\text { Zinc } \\
\text { binuclear } \\
\text { cluster } \\
\text { present? }\end{array}$ \\
\hline $\mathrm{pAL} 7 \Delta \mathrm{GE}$ & pBR325 & no & $q u t A$ & $1-2475$ & NA & Whole of QUTA & yes \\
\hline pATR1 & pCAP2 & pyr-4 & $p g k$ & $1-2475$ & NA & Whole of QUTA & yes \\
\hline pATR3 & pCAP2 & pyr-4 & pgk & $396-2475$ & NA & $\begin{array}{l}\text { Whole of QUTA lacking the } \\
\text { N-terminal (zinc-binuclear- } \\
\text { cluster-containing) } 132 \\
\text { amino acids }\end{array}$ & no \\
\hline pATR4 & pCAP2 & pyr-4 & pgk & $396-1455$ & $\mathrm{NA}$ & $\begin{array}{l}\text { DHQ-synthase-like domain } \\
\text { lacking the N-terminal } \\
\text { (zinc-binuclear-cluster- } \\
\text { containing) } 132 \text { amino acids }\end{array}$ & no \\
\hline pNUFC201 & pNUFC101 & no & pgle & $1-2475$ & $\mathrm{NA}$ & Whole of QUTA & yes \\
\hline pRTA1 & pNUFC101 & pyr-4 & pgk & $\mathrm{NA}$ & $1-2790$ & Whole of QUTR & $\mathrm{NA}$ \\
\hline
\end{tabular}

NA, Not applicable.

Expression from the pgk promoter. In order to determine whether the qut $A$ promoter in the high-copy-number qut $A$ transformants was titrating out the QUTR protein, the qut $A$ gene was placed under the control of the $p g k$ promoter in pNUFC100 to produce pNUFC201 (see Methods for the construction of pNUFC201).

pNUFC201 was used to transform $A$. nidulans strain qut $A 303$ and transformants were selected by their ability to utilize quinate as carbon source. Forty transformants were screened by the in vitro PCA spot test and 13 were found to constitutively produce the three quinate pathway enzymes. DNA from one transformant (A7/1) which was negative in the PCA spot test for constitutivity and from two transformants (A7/5 and A7/6) which were positive in the test was purified and investigated by Southern-blot analysis (data not shown). Transformant $\mathrm{A} 7 / 1$ had one extra copy of the qut $A$ gene, whereas transformant $\mathrm{A} 7 / 5$ had approximately four copies and A7/6 approximately five copies (none of the extra copies had integrated at the qut $A$ locus); in each case the analysis showed that the qut $\mathrm{R}$ genes had not been disrupted.

These results indicate that the QUTR repressor protein does not act solely by binding to the promoter of the qut $A$ gene. It is possible, however, that because we were selecting for the growth of transformants on the basis of having a fully functional QUTA protein, the sample is unrepresentative and may have selected for a class of transformants that contain a rare mutation or rearrangement.

In order to explore this possibility, the experiment was repeated using the qut $A$ gene under the $p g k$ promoter in PATR1. This plasmid includes the selectable marker pyr4 (of $N$. crassa) which can complement the $A$. nidulans pyr $G$ mutation and allow growth in minimal medium lacking uracil; the selection for transformation is therefore independent of the qut $A$ gene in pATR1. $A$. nidulans strain G191 was transformed with plasmids pATR1 (containing the qut $A$ gene under control of the pgk promoter in the vector PCAP2; see Table 4); 40 transformants were screened by the in vitro PCA spot test and 13 were judged to be constitutive (coincidentally, this was an identical number to the experiment described above where the qut $A 303$ strain was transformed with pNUFC201). The levels of qut pathway enzymes in cellfree extracts of four constitutive transformants (TATRK41, 43-45) and one transformant containing unmodified pCAP2 DNA (2043), grown under inducing and non-inducing conditions, are shown in Table 3(b). Southern-blot analysis showed that the qut $\mathrm{R}$ gene had not been disrupted in these transformants (data not shown). Northern-blot analysis of the transformant TATRAK41 demonstrated that a novel qut $A$-specific mRNA of the appropriate size was produced constitutively in this strain, and that the concentration of this mRNA was elevated with respect to the native qut $A \mathrm{mRNA}$ of the wild-type control (see Fig. 1a).

The combined data in Table 3 show that the effect of the QUTR repressor protein can be negated by transforming in multiple copies of the qut $A$ gene under the control of the qut $A$ or $p g k$ promoters in strains either wild-type or mutant for the host qut $A$ gene. The significance of these data lies in the fact that all three quinate pathway enzymes are being produced constitutively in the absence of quinate in some of the transformants and not in the controls, rather than in the values of the specific activities. The apparent enhancement of activity by the addition of quinate in constitutive transformants using the pgk promoter to drive transcription of target DNA sequences is probably a reflection of enhanced mRNA production (see Fig. 1a, and below) which then presumably leads to an increase in the concentration of uncomplexed QUTA protein. Furthermore, the effect of transforming in the multiple copies of the qut $A$ gene is not an artifact produced by the transformation selection process, and the results confirm that the QUTR protein cannot exert its 
effect solely by interacting with the qut $A$ promoter. The simplest interpretation of these data is that an increased copy number of the qut $A$ gene causes an increase in the levels of the QUTA protein and thereby leads to a constitutive phenotype.

\section{Increasing the copy number of qutR leads to a super- repressed phenotype for the quinate utilization pathway}

The coding region of the complete qut $\mathrm{R}$ gene was placed under the control of the $p g k$ promoter and the qutE terminator in pNUFC 101 to produce pRTA1, which also included the selectable marker pyr-4 (see Table 4). Expression directed by this plasmid therefore decouples the production of the QUTR protein from the autoregulatory circuit mediated by the qut $A$ gene (Levesley et al., 1996), and allows an assessment of the in vivo effect of increasing the copy number of the qut $\mathrm{R}$ gene. Failure to ensure uncoupling would make the overproduction of the QUTR protein unlikely, as it would switch off the transcription of qut $A$, whose product (QUTA) is necessary for induction of the qut $\mathrm{R}$ gene under the control of its native promoter (Levesley et al., 1996).

In order to confirm that the qut $R$ gene in $\mathrm{pRTA} 1$ functions normally in vivo, $A$. nidulans strain 2035 (which carries a qut $\mathrm{R}^{c}$ mutation, thereby leading to constitutive expression of the qut pathway enzymes; Lamb et al., 1992) was transformed with pRTA1. Transformants were selected by their ability to grow in minimal medium in the absence of uracil and were subsequently screened in the PCA spot test. More than $95 \%$ of the transformants had a quinateinducible phenotype, demonstrating the presence of a fully functional QUTR protein, whereas the control strain (2035 transformed with pCAP2; Turner \& Ballance, 1987) remained constitutive. These wild-type QUTR proteins could be produced either by integration of the transforming plasmid at a site away from the qut $\mathrm{R}$ locus or by specific integration into the qut $\mathrm{R}$ gene, thereby giving the possibility of producing a hybrid gene that contained parts of the resident and plasmid-borne qut $\mathrm{R}$ genes.

Subsequent Southern-blot analyses (data not shown) of selected transformants showed that integration into sites away from the qut $R$ locus gave a wild-type phenotype, thereby confirming that the qut $\mathrm{R}$ gene in $\mathrm{pRTA} 1$ was functioning normally in vivo. One of these transformants (R1/27, qut $\mathrm{R}$ copy number 4 ) was taken at random and poly $\left(\mathrm{A}^{+}\right)$mRNA prepared from the two halves of a glucose-grown culture, one half of which had been washed free of glucose and incubated in the presence of quinate. The poly $\left(\mathrm{A}^{+}\right)$mRNA from the two halves of the culture was probed for the presence of qutR-specific mRNA by Northern blotting. The results show that qut $R-$ specific mRNA, of the appropriate size, was present in the poly $\left(\mathrm{A}^{+}\right)$mRNA extracted from both cultures (Fig. 1b). This demonstrates that the qutR mRNA was being produced even in the absence of quinate and was therefore decoupled from the QUTA-mediated autoregulatory circuit. We also probed for act $A \mathrm{mRNA}$, as an internal standard, which indicated that there was sixfold more

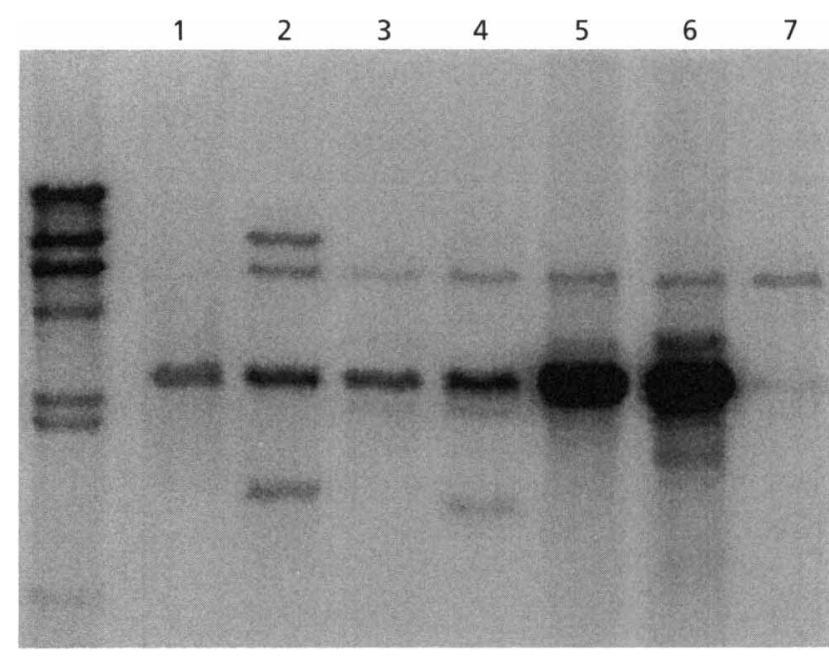

Fig. 2. Southern blot analysis of wild-type and qutR multi-copy transformants. Approximately $15 \mu \mathrm{g}$ of DNA isolated from $A$. nidulans strains transformed with plasmids specifying the entire QUTR protein, and driven by the pgk promoter, was subjected to Southern blotting. The DNA was digested with Ncol prior to electrophoresis, to release the coding region of the qutR gene as a $2.8 \mathrm{~kb}$ fragment. The probe was generated by using nicktranslation to radiolabel a PCR product of the complete qutA coding region with [32P]dCTP. Lane 1 , strain 1-4 (qutR copy number 7); lane 2, strain R1-80 (qutR copy number 3); lane 3, strain R1-64 (qutR copy number 5); lane 4, strain R1-60 (qutR copy number 5); lane 5, strain R1-36 (qutR copy number 23); lane 6, strain R1-19 (qutR copy number 22); lane 7, strain G191 wild-type control (qutR copy number 1). The unlabelled track contains size markers provided by HindIII digestion of lambda DNA. The values for the copy number determination were derived from analysis of a serial twofold dilution series of replicate 'dot-blots', using the act $A$ gene of $A$. nidulans (see the legend to Fig. 1) as an internal marker. The samples shown in this figure are a qualitative representation of the data and show that an extra DNA species of the predicted size $(2.78 \mathrm{~kb})$ was present in each case following Ncol digestion.

$q u t R$-specific mRNA in the half of the culture that had been incubated with quinate (Fig. 1b). This apparent elevation of mRNA levels of heterologous genes fused to the pgk promoter in the presence of quinate has been noted previously, although the level of increase seen was not as great as seen here (Streatfield et al., 1992). The mechanism for this increase in $p g k$-promoter-specific mRNA production in the presence of quinate remains unclear. Our data confirm that the increase in copy numbers of the qut $\mathrm{R}$ gene was associated with an increase in the level of $q u t R$-specific mRNA compared with the control strain 2035, which produced levels of qut $\mathrm{R} \mathrm{mRNA}$ that were undetectable under these conditions.

A. nidulans strain $\mathrm{G} 191$ (which has a wild-type quinateinducible qut gene cluster) was transformed with pRTA1 and transformants were selected by their ability to grow in minimal medium in the absence of uracil. Six transformants, picked at random, were screened by Southernblot analysis in an attempt to identify a range that contained different numbers of integrated qut $\mathrm{R}$ genes (see Fig. 2). Transformants with copy numbers in the range 3 to 23 were identified, and two from the extremes of the 
Table 5. Growth tests and enzyme assays on haploid and diploid strains containing multiple copies of the qutA and qutR genes

(a) Growth tests were carried out on appropriately supplemented minimal medium, using a growth scale of $0-5$, where a score of 5 is the extent of wild-type growth and 0.5 is the 'sparse growth' typical of all quinate-non-utilizing mutants (Grant et al., 1988). (b) The qutE-encoded type II 3-

dehydroquinase levels in the haploid and diploid strains shown were determined in cell-free extracts from mycelium grown with glycerol as carbon source or from mycelium grown with glycerol as carbon source and subsequently induced by the addition of quinate. The extra copies of the qut $A$ and $q u t \mathrm{R}$ genes are under the control of the $p g k$ promoter. The specific activity for the type II 3-

dehydroquinase are shown in parentheses, with the values relative to the appropriate control (given a value of 1) for each of the two sets (haploid and diploid) of transformants. ND, Not detectable.

(a) Growth tests

\begin{tabular}{|lcc|}
\hline Strain* & Glycerol & Quinate \\
\hline R21 & 5 & 5 \\
2043 & 5 & 5 \\
R1-60 & 5 & $3-4$ \\
R1-36 & 5 & $0 \cdot 5$ \\
qut $A 303$ & 5 & $0 \cdot 5$ \\
qutD8 & 5 & $0 \cdot 5$ \\
\hline
\end{tabular}

* R21, wild type control; 2043, the host strain for transformation; R1-60, a multicopy (5 copies) qut $\mathrm{R}$ transformant; R1-36, a multicopy (23 copies) qut $\mathrm{R}$ transformant; qut $A 303$, a negative control with a non functional QUTA protein; qutD8, a negative control with a non-functional quinate permease.

(b) 3-Dehydroquinase levels in haploid and diploids strains containing a range of copy numbers for the qutA and qutR genes

\begin{tabular}{|lcccrc|}
\hline Strain & Ploidy & $\begin{array}{c}\text { 3-Dehydroquinase } \\
\text { activity } \\
\text { glycerol grown }\end{array}$ & $\begin{array}{c}\text { 3-Dehydroquinase } \\
\text { activity } \\
\text { quinate induced }\end{array}$ & $\begin{array}{c}\text { qutA } \\
\text { copy } \\
\text { number }\end{array}$ & $\begin{array}{c}\text { qutR } \\
\text { copy } \\
\text { number }\end{array}$ \\
\hline 2043 & $\mathrm{~N}$ & ND & $1 \cdot 00(0 \cdot 890)$ & 1 & 1 \\
R1-60 & $\mathrm{N}$ & ND & $0 \cdot 60(0 \cdot 530)$ & 1 & 5 \\
R1-36 & $\mathrm{N}$ & ND & $0 \cdot 06(0 \cdot 054)$ & 1 & 23 \\
2043/R153 & 2N & ND & $1 \cdot 00(0 \cdot 530)$ & 2 & 2 \\
TATRA 95/R153 & 2N & $1 \cdot 00(0 \cdot 232)$ & $1 \cdot 35(0 \cdot 730)$ & 17 & 2 \\
TATRA 95/R1-60 & 2N & $0 \cdot 53(0 \cdot 122)$ & $1 \cdot 70(0 \cdot 920)$ & 17 & 6 \\
TATRA 95/R1-36 & 2N & ND & $0 \cdot 42(0 \cdot 230)$ & 17 & 24 \\
\hline
\end{tabular}

range, R1-60 (5 copies of qutR) and R1-36 (23 copies of $q u t R)$, were screened for their ability to produce quinate pathway enzymes and to utilize quinate as carbon source. As shown in Table 5, with an increase in the copy number of the qut $R$ gene there was a decreasing ability to utilize quinate as carbon source, and an associated lowering of the in vivo levels of the quinate pathway enzymes.

Southern-blot analysis also showed that the qut $A$ gene in these multi-copy qut $\mathrm{R}$ transformants had not been disrupted (data not shown), precluding this as an explanation for the inability of transformant R1-36 to utilize quinate as a carbon source (a super-repressed phenotype). The simplest interpretation of these data is that, in these transformants, an elevated copy number of the qut $R$ gene is correlated with an increased concentration of the QUTR protein, thereby producing a super-repressed phenotype.

\section{Combining the super-repressed and constitutive phenotypes in a diploid strain produces an inducible phenotype}

If the QUTR protein does mediate its repressing effect on transcriptional regulation by a direct interaction with the QUTA protein, then increasing the concentration of the QUTR protein in a multi-copy qut $A$ constitutive transformant should restore the wild-type inducible phenotype. The direct transformation of qut $\mathrm{R}$-containing plasmids into a multi-copy qut $A$ constitutive transformant could lead to an inducible phenotype by integration into and inactivation of one or more of the qut $A$ genes essential to maintain the constitutive phenotype. In order to obviate this possible problem, the facility to produce stable diploid strains in $A$. nidulans was exploited to bring together multi-copy qut $A$ (constitutive) and qut $\mathrm{R}$ (super- 
repressed) haploid strains. The rationale was to combine the constitutive transformant strain TATRA95 (containing potentially 15 functional copies of qut $A$ under its own promoter, as transformant TATRA95 was generated by transforming a qut $A^{-}$strain), with the multi-copy qut $\mathrm{R}$ transformant strains R1-60 (5 copies of qut $\mathrm{R}$; reduced growth on quinate) and R1-36 (23 copies of qut $R$; unable to utilize quinate; super-repressed). The transcription of these extra qutR genes was decoupled from the QUTAmediated autoregulatory circuit by the substitution of the pgk promoter for the wild-type quinate-inducible promoter, as described above.

Multi-copy qut $A$ transformant TATRA95 was made diploid with the wild-type strain R153 and with the two multi-copy qut $\mathrm{R}$ transformants R1-60 and R1-36. The various diploids were screened for the ability of quinate to induce production of the quinate pathway enzymes. The results are shown in Table 5, and demonstrate that an increase in the copy number of the qut $\mathrm{R}$ gene relative to the copy number of the qut $A$ gene in the constitutive strain reduced or, in the case of the diploid with R1-36, eliminated the constitutive phenotype. The effect of the extra copies of the qut $\mathrm{R}$ gene was also manifest under inducing conditions, as the diploid with $\mathrm{R} 1-36$ (24 copies of the qut $R$ gene due to the extra qut $R$ gene provided by the TATRA95 haploid) was only able to induce the production of the quinate pathway enzymes to approximately half the wild-type level. The biological effects seen in these transformants are therefore correlated with qut $R$ gene copy number.

The simplest interpretation of these data is that an elevated qut $R$ copy number is associated with elevated QUTR production, and that the QUTR repressor protein mediates its effects by a direct interaction with the QUTA activator protein.

\section{Deletion analysis of the QUTA protein}

In order to further test the hypothesis that the QUTR protein interacts directly with the QUTA protein, and to attempt to localize the region of the QUTA protein that mediates this putative interaction, various overlapping subregions of the QUTA protein were produced in $A$. nidulans in the presence of wild-type levels of correctly regulated wild-type intact QUTA protein. The rationale behind these experiments was to produce, in vivo, deleted versions of the QUTA protein that lacked the DNAbinding domain; if these could bind to (and effectively 'mop up') the QUTR repressor protein, the endogenous wild-type QUTA protein should be relieved from repression by the endogenous QUTR protein, resulting in a constitutive phenotype.

DNA sequences specifying QUTA protein fragments consisting of (a) the bi-domain QUTA protein lacking the $\mathrm{N}$-terminal (zinc-binuclear-cluster-containing) 132 amino acids (plasmid pATR3); or (b) the N-terminal DHQsynthase-like domain lacking the $\mathrm{N}$-terminal 132 amino acids, and also lacking the C-terminal EPSP-synthase like domain (plasmid pATR4), were placed under the control of the $p g k$ promoter in the vector $\mathrm{pCAP} 2$. These plasmids were transformed (using selection for uracil independence) into $A$. nidulans strain G191 that produces wildtype levels of correctly regulated native QUTA protein. The nucleotide coordinates of the qut $A$ gene expressed in $A$. nidulans and driven by the $p g k$ promoter are given in Table 4.

When the sequences encoding both of the QUTA protein domains but lacking the $\mathrm{N}$-terminal zinc binuclear motif (pATR3) were expressed in $A$. nidulans, the use of the spot test demonstrated that a constitutive phenotype could be generated ( 53 transformants out of a total of 258 tested). Three transformants that showed a constitutive phenotype in the spot test (TATRK195, 202 and 251), one that showed an inducible phenotype (TATRK189), and the wild-type control strain 2043 (strain G191 transformed with unmodified pCAP2 DNA) were directly tested for the presence of the quinate pathway enzymes in cell-free extracts. The results of these enzyme assays are shown in Table 3(c); they confirm that the constitutive transformants are indeed producing the quinate pathway enzymes in the absence of quinate. Northern-blot analysis of one randomly selected transformant (TATRK251) demonstrated that the size of the constitutively produced qut $A$-specific mRNA directed by pATR3 was appropriately smaller than the mRNA directed by plasmids specifying the complete QUTA protein (see Fig. 1a). Additionally, the truncated qut $A$-specific mRNA was produced to an elevated concentration compared to the wild-type control (see Fig. 1a). When the sequence encoding the N-terminal DHQ-synthase-like domain of QUTA but lacking the zinc binuclear cluster motif (pATR4) was expresssed in $A$. nidulans, the use of the spot test was unable to detect a constitutive phenotype ( 0 out of 111 transformants tested).

The simplest interpretation of these data is that in the transformants selected for their ability to grow in minimal medium lacking uracil, a range of overproduction of the sub-regions of the QUTA protein was occurring. Furthermore, in the case of pATR3, these subregions are proposed to bind to the QUTR repressor protein and to block the site(s) necessary for a normal stoichiometric interaction with the intact QUTA protein, thereby relieving the endogenous native QUTA protein from repression.

The observation that the truncated QUTA protein encoded by pATR4 does not apparently lead to a constitutive phenotype suggests that the QUTR protein may recognize and bind to the C-terminal EPSP-synthaselike domain of QUTA. This interpretation must be viewed with caution, however, as the truncated protein specified by pATR4 may simply not fold correctly or may be very unstable; either explanation could account for the apparent inability to generate constitutive transformants.

\section{Conclusions}

In the experiments described here, we have designed a strategy to elevate the expression in vivo of the qut $A$ and $q u t R$ genes, and hence of the QUTA and QUTR proteins, 
and we have examined the consequences on the regulation of the quinate utilization pathway. The strategy that we selected was to create multicopy transformant strains that included integrated copies of the qut $A$ and qut $\mathrm{R}$ genes under the control of the pgk promoter. The purpose behind the use of the $p g k$ promoter was to decouple the transcription of the genes under its control from the action of the QUTA activator protein. This strategy proved successful in that transcription was driven from the pgk promoter in the absence of quinate, but this transcription, at least in the case of qut $\mathrm{R}$, was shown to be further enhanced by the addition of quinate. The mechanism for this enhancement of transcription from the isolated $p g k$ promoter by the presence of quinate remains unclear. That expression driven by the isolated $p g k$ promoter drives the production of functional protein products was confirmed by rescue of a qut $E$ mutation by the heterologous qa-2 gene. Transformant strains with multiple copies of the qut $A$ gene under the control of the $p g k$ promoter, or indeed its own promoter, showed a constitutive phenotype and the elevated expression of the qut $A$ mRNA was confirmed. Transformant strains with multiple copies of the qut $\mathrm{R}$ gene showed a super-repressed phenotype and the elevated expression of the qut $\mathrm{R} \mathrm{mRNA}$ was similarly confirmed. When multicopy qut $A$ (constitutive phenotype) and qut $R$ (super-repressed phenotype) haploid strains were brought together in diploids, a wildtype inducible phenotype was restored. Multicopy transformant strains expressing a qut $A$ gene encoding a truncated QUTA protein also showed a constitutive phenotype, indicating that QUTR-mediated repression is independent of the amino-terminal 132 amino acids of QUTA, which includes the DNA-binding domain.

These data are consistent with three alternative interpretations for how the QUTR protein mediates its repressing effect. Firstly, the elevated levels of the QUTR protein may lead to elevated levels of a second molecule(s), which directly interacts with the QUTA protein and thereby inactivates it. Genetic analysis strongly implies that the qut $\mathrm{R}$ gene (and the homologous qa-1S gene of $N$. crassa) encodes a repressor (Grant et al., 1988; Giles et al., 1985; Geever et al., 1989) and it is possible, therefore, that elevated levels of the QUTR protein could act to repress the transcription of a putative second gene encoding the true repressor protein, thereby leading to a constitutive phenotype. This is unlikely, as the gene encoding this second putative repressor should have been identified in the mutant screens that were originally employed to generate and analyse the qut and qa mutants of $A$. nidulans and N. crassa (Grant et al.,1988; Giles et al., 1985). Furthermore, the QUTR and QA-1S proteins have no recognized motifs capable of DNA binding (Hawkins $e t$ al., 1992; Huiet \& Giles, 1986) and are therefore unlikely to act by binding to promoter regions to inhibit transcription, or to act as DNA-dependent activators of the transcription of a second repressor gene.

Secondly, the QUTR protein may mediate its repressing effect by potentiating a pool of small organic effector molecules, which subsequently bind to and inactivate the QUTA protein pool. The mechanism for such a putative effect could be enzymic. For example, the N-terminal sequence of the QUTR and QA-1S proteins are homologous with shikimate kinase and both contain a completely conserved purine nucleotide binding motif; it is possible therefore that this domain could have in vivo kinase activity (Anton $e t$ al., 1987; Hawkins et al., 1992; Walker et al., 1982). Such an enzymic mechanism is highly unlikely to be dependent on the copy number of the extra $q u t \mathrm{R}$ genes that were introduced into the transformed strains. We note, in addition, that the other two domains of the QUTR protein (dehydroquinase-like and shikimate-dehydrogenase-like) have been screened in an extremely sensitive in vivo assay for enzyme activity in E. coli, but no such activity was detected (Lamb et al., 1996).

Thirdly, the QUTR protein may mediate its repressing effect on the QUTA protein by a direct protein--protein interaction with the QUTA protein. In this respect, we note that there are significant comparisons to be made with genetic experiments undertaken to understand the control of galactose utilization in Saccharomyces cerevisiae. The GAL4 protein is a positively acting transcriptionactivating protein responsible for switching on the transcription of the genes necessary for the utilization of galactose when this sugar is given as a carbon source. The GAL80 protein is a negatively acting transcriptionregulating protein that mediates its action on galactose utilization by a post-translational interaction with the GAL4 protein (for a review see Johnston, 1987). Certain dominant alleles encoding a mutant GAL4 protein that produced the galactose pathway enzymes constitutively in the absence of galactose were shown to complement some dominant mutant alleles encoding a super-repressing GAL80 protein. The resulting diploid strains had the wild-type inducible phenotype and proved to be the first evidence that the GAL4 and GAL80 proteins directly interacted with one another (Nogi et al., 1977).

Taking together the complete package of in vivo experiments described here, and viewing the results in the light of previous genetic analysis in both $A$. nidulans and $N$. crassa, and biological precedent, we believe that the most likely interpretation of the data is that the QUTR protein mediates its repressing effect by directly interacting with the QUTA protein.

\section{ACKNOWLEDGEMENTS}

This research was supported by UK Research Council funding. We thank Dr Alan Radford, University of Leeds, for kindly providing plasmid $\mathrm{pFB} 4$.

\section{REFERENCES}

Anton, I. A., Duncan, K. \& Coggins, J. R. (1987). A eukaryotic repressor protein, the qa-1S gene product of Neurospora crassa, is homologous to part of the arom multifunctional enzyme. $J$ Mol Biol 197, 367-371.

Beri, R. K., Whittington, H., Roberts, C. F. \& Hawkins, A. R. (1987). Isolation and characterisation of the positively acting regulatory gene qut $A$ from Aspergillus nidulans. Nucleic Acids Res 15, 7991-8001. 
Beri, R. K., Grant, S., Roberts, C. F., Smith, M. \& Hawkins, A. R. (1990). Selective over-expression of the qutE gene encoding catabolic 3-dehydroquinase in multicopy transformants of Aspergillus nidulans. Biocbem J 265, 337-342.

Bugg, T. D. H., Alefounder, P. R. \& Abell, C. (1991). An amino acid sequence motif observed amongst enzymes of the shikimate pathway. Biocbem J 276, 841-843.

Buxton, F. P. \& Radford, A. (1983). Cloning of the structural gene for orotidine 5 '-monophosphate carboxylase of Neurospora crassa by expression in Escbericbia coli. Mol Gen Genet 190, 403-405.

Case, M. E., Giles, N. H. \& Doy, C. H. (1972). Genetical and biochemical evidence for further interrelationships between the polyaromatic synthetic and the quinate-shikimate catabolic pathways in Neurospora crassa. Genetics 71, 337-348.

Cathala, G., Savouret, J. F., Mendez, B., West, B. L., Karin, B., Martial, J. A. \& Baxter, J. D. (1983). A method for isolation of intact translationally active ribonucleic acid. DNA 2, 329-335.

Charles, I. G., Keyte, J. W., Brammar, W. J., Smith, M. \& Hawkins, A. R. (1986). The isolation and nucleotide sequence of the complex arom locus of Aspergillus nidulans. Nucleic Acids Res 14, 2201-2213.

Clements, J. M. \& Roberts, C. F. (1985). Molecular cloning of the 3phosphoglycerate kinase (PGK) gene from Aspergillus nidulans. Curr Genet 9, 293-298.

Clements, J. M. \& Roberts, C. F. (1986). Transcription and processing signals in the 3-phosphoglycerate kinase (PGK) gene from Aspergillus nidulans. Gene 14, 97-105

Fidel, S., Doonan, J. H. \& Morris, N. R. (1988). Aspergillus nidulans contains a single actin gene which has unique intron locations and encodes a $\gamma$-actin gene. Gene 70, 283-293.

Geever, R. F., Huiet, I., Baum, J. A., Tyler, B. M., Patel, V. B., Rutledge, B. J., Case, M. E. \& Giles, N. H. (1989). DNA sequence, organisation, and regulation of the $Q A$ gene cluster of Neurospora crassa. J Mol Biol 207, 15-34.

Giles, N. H. (1978). The organisation, function and evolution of gene clusters in eukaryotes. Am Nat 112, 641-657.

Giles, N. H., Case, M. E., Baum, J., Geever, R., Huiet, L., Patel, V. \& Tyler, B. (1985). Gene organisation and regulation in the qa (quinic acid) gene cluster of Neurospora crassa. Microbiol Rev 49, 338-358.

Glazebrook, J. A., Mitchell, K. \& Radford, A. (1987). Molecular genetic analysis of the pyr-4 gene of Neurospora crassa. Mol Gen Genet 209, 399-402.

Grant, S., Roberts, C. F., Lamb, H. K., Stout, M. \& Hawkins, A. R. (1988). Genetic regulation of the quinic acid utilization $(q u t)$ gene cluster in Aspergillus nidulans. J Gen Microbiol 134, 347-358.

Grewe, R. \& Haendler, H. (1966). 5-Dehydroquinic acid. Biochem Prep 11, 21-26.

Hawkins, A. R. (1987). The complex arom locus of Aspergillus nidulans: evidence for multiple gene fusions and convergent evolution. Curr Genet 11, 491-498.

Hawkins, A. R. \& Lamb, H. K. (1995). The molecular biology of multidomain proteins. Selected examples. Eur J Biochem 232, 7-18.

Hawkins, A. R. \& Smith, M. (1991). Domain structure and interaction within the pentafunctional AROM polypeptide. Eur $J$ Biocbem 196, 717-724.

Hawkins, A. R., Da Silva, A. J. \& Roberts, C. F. (1985). Cloning and characterisation of the three enzyme structural genes $q u t B, q u t C$ and $q u t E$ from the quinic acid utilisation gene cluster in Aspergillus nidulans. Curr Genet 9, 305-311.

Hawkins, A. R., Lamb, H. K., Smith, M., Keyte, J. W. \& Roberts, C. F. (1988). Molecular organisation of the quinic acid utilisation (qut) gene cluster in Aspergillus nidulans. Mol Gen Genet 214, 224-231.
Hawkins, A. R., Lamb, H. K. \& Roberts, C. F. (1992). Structure of the Aspergillus nidulans qut repressor-encoding gene: implications for the regulation of transcription initiation. Gene 110, 109-114.

Hawkins, A. R., Lamb, H. K., Moore, J. D., Charles, I. G. \& Roberts, C. F. (1993a). The pre-chorismate (shikimate) and quinate pathways in filamentous fungi: theoretical and practical aspects. $J$ Gen Microbiol 139, 2891-2899.

Hawkins, A. R., Lamb, H. K., Moore, J. D. \& Roberts, C. F. (1993b). Genesis of eukaryotic transcriptional activator and repressor proteins by splitting a multidomain anabolic enzyme. Gene 136, 49-54.

Hawkins, A. R., Moore, J. D. \& Adeokun, A. M. (1993c). Characterisation of the 3-dehydroquinase domain of the pentafunctional AROM protein, and the quinate dehydrogenase from Aspergillus nidulans, and the overproduction of the type II 3-dehydroquinase from Neurospora crassa. Biochem J 296, 451-457.

Hemsley, A., Arnheim, N., Toney, M. D., Cortopassi, G. \& Galas, D. J. (1989). A simple method for site-directed mutagenesis using the polymerase chain reaction. Nucleic Acids Res 17, 6545-6551.

Huiet, L \& Giles, N. H. (1986). The qa repressor of Neurospora crassa; wild-type and mutant nucleotide sequences. Proc Natl Acad Sci US $A$ 83, 3381-3385.

Johnston, M. (1987). A model fungal regulatory mechanism: the GAL genes of Saccharomyces cerevisiae. Microbiol Rev 51, 458-476.

Kinghorn, J. R. \& Hawkins, A. R. (1982). Cloning and expression in Eschericbia coli $\mathrm{K}-12$ of the biosynthetic dehyroquinase function of the arom cluster gene from the eukaryote Aspergillus nidulans. Mol Gen Genet 186, 145-152.

Lamb, H. K., Hawkins, A. R., Smith, M., Harvey, I. J., Brown, J., Turner, G. \& Roberts, C. F. (1990). Spatial and biological characterisation of the complete quinic acid utilisation gene cluster in Aspergillus nidulans. Mol Gen Genet 223, 17-23.

Lamb, H. K., Bagshaw, C. R. \& Hawkins, A. R. (1991). In vivo overproduction of the pentafunctional AROM polypeptide in Aspergillus nidulans affects metabolic flux in the quinate pathway. Mol Gen Genet 227, 187-196.

Lamb, H. K., Van den Hombergh, J. P. T. W., Newton, G. H., Moore, J. D., Roberts, C. F. \& Hawkins, A. R. (1992). Differential flux through the quinate and shikimate pathways: implications for the channeling hypothesis. Biocbem J 284, 181-187.

Lamb, H. K., Moore, J. D., Lakey, J. H., Levett, L., Wheeler, K. A., Lago, H., Coggins, J. R. \& Hawkins, A. R. (1996). Comparative analysis of the QUTR transcription repressor protein and the three C-terminal domains of the pentafunctional AROM enzyme. Biochem J 313, 941-950.

Levesley, I., Newton, G. H., Lamb, H. K., van Schothorst, E., Dalgleish, R. W. M., Samson, A. C. R., Roberts, C. F. \& Hawkins, A. R. (1996). Domain structure and function within the QUTA protein of Aspergillus nidulans: implications for the control of transcription. Microbiology 142, 87-98.

Maniatis, T., Fritsch, E. F. \& Sambrook, J. (1982). Molecular Cloning: a Laboratory Manual. Cold Spring Harbor, NY : Cold Spring Harbor Laboratory.

Moore, J. D. \& Hawkins, A. R. (1993). Overproduction of, and interaction within, bifunctional domains from the amino- and carboxy-termini of the pentafunctional AROM protein of Aspergillus nidulans. Mol Gen Genet 240, 92-102.

Moore, J. D., Lamb, H. K., Garbe, T., Servos, S., Dougan, G., Charles, I. G. \& Hawkins, A. R. (1992). Inducible overproduction of the Aspergillus nidulans pentafunctional AROM protein and the type-I and -II 3-dehydroquinases from Salmonella typhi and Mycobacterium tuberculosis. Biocbem J 287, 173-181. 
Nogi, Y., Matsumoto, K. \& Oshima, Y. (1977). Interaction of superrepressible and dominant constitutive mutations for the synthesis of galactose pathway enzymes in Saccharomyces cerevisiae. Mol Gen Genet 152, 137-144.

Streatfield, S. J., Toews, S. \& Roberts, C. F. (1992). Functional analysis of the expression of the $3^{\prime}$-phosphoglycerate kinase $p g k$ gene in Aspergillus nidulans. Mol Gen Genet 233, 231-240.

Turner, G. \& Ballance, D. J. (1987). In Proceedings of the Fifth International Symposium on the Genetics of Industrial Micro-Organisms. Edited by M. Alacevic, E. Hraneuli \& Z. Toman. Zagreb, Yugoslavia: Pliva.

Van den Hombergh, J. P. T. W., Moore, J. D., Charles, I. G. \& Hawkins, A. R. (1992). Overproduction in Escherichia coli of the dehydroquinate synthase domain of the Aspergillus nidulans pentafunctional AROM protein. Biochem $J$ 284, 861-867.
Walker, J. E., Saraste, M., Runswick, M. J. \& Gay, N. J. (1982). Distantly related sequences in the alpha-subunits and beta-subunits of ATP synthases, myosin, kinases, and other ATP-requiring enzymes and a common nucleotide binding fold. EMBO $J 1$, 945-951.

Wheeler, K. A., Lamb, H. K. \& Hawkins, A. R. (1996). Control of metabolic flux through the quinate pathway in Aspergillus nidulans. Biochem J 315, 195-205.

Whittington, H. A., Grant, S., Roberts, C. F., Lamb, H. K. \& Hawkins, A. R. (1987). Identification and isolation of a putative permease gene in the quinic acid utilisation $(q u t)$ gene cluster of Aspergillus nidulans. Curr Genet 12, 135-139.

Received 6 November 1995; revised 3 January 1996; accepted 15 January 1996. 